\title{
PENGARUH DUKUNGAN ORGANISASI, KESESUAIAN NILAI DAN EMPLOYEE RESILIENCE TERHADAP KOMITMEN ORGANISASI PD BPR BKK PURWOKERTO
}

\author{
Sungging Darupaksi ${ }^{*}$ \\ ${ }^{1 *}$ Magister Manajemen, Fakultas Ekonomi dan Bisnis Universitas Jenderal Soedirman \\ Purwokerto Indonesia \\ *Email corresponding author: sungging_darupaksi@yahoo.com
}

\begin{abstract}
ABSTRAK
Tujuan penelitian ini adalah untuk mengetahui pengaruh dukungan organisasi, kesesuaian nilai, dan employee resilience terhadap organizational commitment. Jenis penelitian ini merupakan penelitian kuantitatif dengan menggunakan metode survey. Populasi dari penelitian ini adalah semua karyawan PD BPR BKK Purwokerto yang masih aktif menjalankan pekerjaannya. Metode pengambilan sampel menggunakan metode Area Proporsional Random Sampling (APRS) sebanyak 190 responden. Hasil penelitian ini menunjukkan bahwa dukungan organisasi berpengaruh positif terhadap organizational commitment karyawan PD BPR BKK Purwokerto. Kesesuaian nilai berpengaruh positif terhadap organizational commitment karyawan PD BPR BKK Purwokerto. Employee resilience berpengaruh positif terhadap organizational commitment karyawan PD BPR BKK Purwokerto.
\end{abstract}

Kata Kunci: Organisasi, Employee Resilience, BPR

\section{ABSTRACT}

The purpose of this study was to determine the effect of organizational support, value appropriateness, and employee resilience on organizational commitment. This type of research is a quantitative study using a survey method. The population of this study were all employees of PD BPR BKK Purwokerto who are still actively carrying out their work. The sampling method used was proportional area random sampling (APRS) as many as 190 respondents. The results of this study indicate that organizational support has a positive effect on organizational commitment of employees of PD BPR BKK Purwokerto. Value suitability has a positive effect on organizational commitment of employees of $P D$ BPR BKK Purwokerto. Employee resilience has a positive effect on organizational commitment of employees of PD BPR BKK Purwokerto.

Keyword: Organization, Employee Resilience, $B P R$

\section{PENDAHULUAN}

Isu pengembangan sumber daya manusia merupakan hal yang penting dalam psikologi industri dan organisasi. Hal ini perlu dilakukan mengingat persaingan industri dalam segala bidang saat ini semakin ketat, tidak terkecuali pada industri perbankan. Organisasi dengan sumber daya manusia yang baik akan mempunyai kekuatan untuk menghadapi persaingan, di mana karyawan menyumbangkan berbagai kemampuan dan usaha ekstra secara berkelanjutan disertai peningkatan produktivitas untuk kemajuan usaha (Mathis \& Jackson, 2006).

Salah satu industri perbankan yang turut dalam persaingan dalam memperebutkan konsumen adalah Bank Perkreditan Rakyat (BPR). PD BPR BKK saat ini adalah berdasarkan Perda No.11 Tahun 2008 Tentang PD BPR BKK di Provinsi Jawa Tengah sebagaimana telah diubah dengan Perda No.3 Tahun 2012. PD BPR BKK Purwokerto memiliki 1 Kantor Pusat yang juga menjadi Kantor Pusat Operasional yang berkedudukan di Jl. R.A. Wiriaatmaja No. 44 Purwokerto, Kabupaten Banyumas, Jawa Tengah serta 24 Kantor Cabang yang tersebar di seluruh Kecamatan di wilayah Kabupaten Banyumas. PD BPR BKK Purwokerto diharapkan memberikan dukungan dan kemampuan yang matang di dalam memberikan layanan perbankan, terutama layanan kredit dari yang kecil hingga yang besar.

Faktor penting dalam dunia perbankan adalah performa bank, karena bank merupakan bisnis jasa dengan kepercayaan yang menjadi landasan bagi konsumen dan performa bank 
adalah salah satu faktor yang dijadikan alasan konsumen menggunakan jasa suatu bank. Performa bank tidak lepas dari komitmen para karyawannya dalam bekerja memberikan pelayanan yang memuaskan kepada para nasabah sehingga performa bank akan meningkat. Karyawan dengan komitmen organisasi yang tinggi menghasilkan performa kerja yang tinggi, rendahnya tingkat absensi dan rendahnya tingkat keluar-masuk (turnover) karyawan.

Menurut informasi yang diperoleh peneliti saat studi awal, di beberapa unit PD BPR BKK Purwokerto masih ditemukan karyawan yang tingkat absensinya cukup rendah atau terlambat datang melebihi jam kantor yang telah ditentukan. Informasi tersebut didukung oleh data absensi dari biro HRD PD BPR BKK Purwokerto pada 3 bulan terakhir yaitu bulan Agustus, September dan Oktober tahun 2019 yang dapat dilihat pada tabel di bawah ini.

Tabel 1. Laporan rekapitulasi absensi karyawan PD BPR BKK Purwokerto

\begin{tabular}{lcccc}
\hline \multicolumn{1}{c}{ Bulan } & Sakit & Ijin & Tanpa keterangan & Terlambat \\
\hline Agustus & 5 & 4 & 3 & 4 \\
\hline September & 1 & 2 & 5 & 8 \\
\hline Oktober & 3 & 5 & 4 & 7 \\
\hline
\end{tabular}

Sumber: HRD PD BPR BKK Purwokerto, November 2019

Data absensi yang tercantum pada tabel di atas menunjukkan masih ada karyawan PD BPR BKK Purwokerto yang datang terlambat, tidak masuk kerja tanpa keterangan atau tanpa memberitahukan kepada atasan unit kerjanya. Data kondisi absensi karyawan $\quad$ PD BPR BKK Purwokerto tersebut dapat menggambarkan komitmen organisasi karyawan yang belum maksimal. Karyawan yang memiliki komitmen organisasi tinggi selalu berupaya melakukan pekerjaan sesuai peraturan perusahaan dan mengerjakan semua tugas dan tanggung jawabnya semaksimal mungkin.

Komitmen organisasi ialah tingkat keyakinan karyawan dan menerima tujuan organisasional serta memiliki keinginan untuk tetap bersama organisasi, atau akan meninggalkan organisasi yang terefleksi dari ketidakhadiran dan perputaran karyawan (Mathis \& Jackson, 2006). Organizational commitment (OC) berpengaruh positif terhadap kinerja perusahaan, karena komitmen sangat berkaitan dengan kesediaan (willingness) dan motivasi individu untuk mencapai sasaran kinerja (Chen \& Francesco, 2003).

Faktor yang dapat mempengaruhi komitmen organisasi adalah dukungan organisasi. Karyawan yang merasa bahwa organisasi ditempatnya bekerja memberikan dukungan, menghargai hasil kerja dan peduli akan kesejahteraan karyawan, maka karyawan akan cenderung lebih berkomitmen terhadap organisasinya (Eisenberger dan Rhoades, 2002). Eisenberger et al., (1990) pada penelitiannya mengungkapkan bahwa karyawan yang memperoleh dukungan dari organisasinya berkecenderungan tidak berpindah ke pekerjaan lain atau akan menolak tawaran kerja dari perusahaan lainnya.

Faktor lain yang tidak kalah penting adalah kesesuaian nilai organisasi dengan nilai-nilai individu/karyawan, karena hal ini akan berimplikasi pada meningkatnya komitmen dan outcomes individu sehingga akan berujung pada keunggulan strategis yang berkelanjutan bagi organisasi. Hasil penelitian Finegan (2000) menunjukkan bahwa kesesuaian nilai berpengaruh positif terhadap komitmen organisasi, baik pada komitmen afektif, kotinuen maupun komitmen normatif. Penelitian lain yang dilakukan oleh Esra et al., (2013) menunjukkan hasil bahwa kesesuaian nilai individu dan nilai organisasi berpengaruh negatif terhadap komitmen organisasi. 
Faktor selanjutnya adalah employee resilience. Hasil penelitian Paul et al., (2016) menunjukkan bahwa employee resilience berpengaruh positif terhadap komitmen organisasi. Di sisi lain, hasil penelitian Atmoko dan Listiara (2012) menunjukkan bahwa employee resilience berpengaruh negatif terhadap komitmen organisasi.

\section{KOMITMEN ORGANISASI (ORGANIZATIONAL COMMITMENT)}

Komitmen organisasional (Organizational Commitment) didefinisikan sebagai ikatan psikologis yang mengindikasikan adanya keterikatan antara individu dengan organisasi yang dapat menjadi alasan bagi individu untuk tetap mempertahankan keanggotaannya dalam organisasi Allen \& Meyer (1990). Komitmen organisasi seorang karyawan dapat diukur melalui beberapa indikator yang dikemukakan oleh Allen \& Meyer (1990) berdasarkan tiga dimensi yaitu (1) Affective commitment (komitmen afektif); individu dengan komitmen afektif tinggi punya kedekatan emosional erat pada organisasi. Berdasar beberapa penelitian. Komitmen afektif berhubungan erat dengan ketidakhadiran dalam organisasi. Individu dengan komitmen afektif tinggi biasanya lebih mendukung kebijakan perusahaan dibanding yang komitmennya lebih rendah. (2) Continuance commitmen (komitmen berkelanjutan), individu dengan komitmen keberlanjutan tinggi akan bertahan dalam organisasi karena sadar akan rugi besar bila meninggalkan organisasi. (3) Normative commitment (komitmen normatif), individu dengan komitmen normatif tinggi akan bertahan dalam organisasi karena kewajiban atau tugas. Perasaan seperti ini dapat memotivasi individu berperilaku baik dan bertindak tepat bagi organisasi.

\section{DUKUNGAN ORGANISASI (ORGANIZATIONAL SUPPORT)}

Mathis \& Jackson (2006) mengemukakan dukungan organisasi merupakan dukungan yang diberikan organisasi pada pegawai berbentuk pelatihan, peralatan, harapan dan tim kerja yang produktif. Robbins et al. (2013) mendefinisikan persepsi dukungan organisasi sebagai tingkat keyakinan karyawan akan kepedulian organisasi dan penghargaannya pada kontribusi dan kesejahteraan karyawan. Eisenberger et al. (2002) berpendapat bahwa tingkat persepsi dukungan organisasi dapat diukur dengan tiga indikator, yaitu dukungan pimpinan, penghargaan dan lingkungan kerja. Persepsi yang baik diantara karyawan akan menumbuhkan perasaan hutang budi karena menganggap organisasi sudah mendukung penuh maka muncullah sikap membalas budi ditunjukkan dengan tingginya komitmen organisasi.

\section{KESESUAIAN NILAI (VALUE CONGRUENCE)}

Edward dan Cable (2009) mengemukakan bahwa kesesuaian nilai merupakan nilai kerja yang amat dibutuhkan seseorang agar nilai kerjanya mampu menunjang kesuksesannya dalam meraih tujuan kerja. Robbins et al. (2013) menyatakan bahwa kesesuaian nilai individu dengan budaya organisasi mendasari kepuasan kerja, komitmen organisasi dan rendahnya turnover. Kristof (1996) berpendapat bahwa ada empat unsur yang digunakan untuk mengukur kesesuaian nilai individu dan organisai, yakni kesesuaian nilai pada individu dan organisasi, kesesuaian tujuan dari individu dan organisasi, kesesuaian kebutuhan individu dan lingkungan kerja dengan sistem dan struktur organisasi, dan kesesuaian kepribadian individu dengan iklim/budaya yang ada dalam organisasi.

\section{RESILIENSI KARYAWAN (EMPLOYEE RESILIENCE)}

Resiliensi ialah satu fenomena yang terkarakterkan melalui pola adaptasi positif terhadap kesulitan dan resiko yang signifikan (Masten dan Reed, 2002). Resiliensi bukan hanya mencakup 
kemampuan bertahan dan kegigihan dalam mengahadapi permasalahan, namun juga secara positif melakukannya walau harus meninggalkan keadaan normal atau titik ekuilibrium. Jadi resiliensi adalah kapasitas untuk bertahan secara gigih dalam menghadapi kesulitan, konflik, kegagalan atau kejadian positif dan peningkatan tanggung jawab (Luthans et al., 2007). Grotberg (1996) mengemukakan bahwa resilience merupakan kemampuan manusia dalam menghadapi, mengatasi dan kuat menghadapi rintangan dan hambatan. Indikator resiliensi yang digunakan pada penelitian ini mengacu pada definisi resiliensi dari Grotberg (1996) yaitu kemampuan menghadapi masalah, kemampuan mengatasi masalah, dan menjadi individu yang lebih kuat.

\section{HIPOTESIS}

H1: Dukungan organisasi berpengaruh positif terhadap organizational commitment.

H2. Kesesuaian nilai berpengaruh positif terhadap organizational commitment.

H3. Employee resilience berpengaruh positif terhadap organizational commitment.

\section{METODE PENELITIAN}

Jenis penelitian ini merupakan penelitian kuantitatif dengan menggunakan metode survey. Populasi dari penelitian ini adalah semua karyawan PD BPR BKK Purwokerto yang masih aktif menjalankan pekerjaannya. Metode pengambilan sampel menggunakan metode Area Proporsional Random Sampling (APRS) sebanyak 190 responden. Sumber data primer diperoleh langsung dari jawaban karyawan PD BPR BKK Purwokerto melalui kuesioner.

\section{HASIL PENELITIAN}

\section{Uji Validitas}

Pengujian validitas instrumen berupa kuesioner menggunakan teknik korelasi product moment. Uji validitas untuk mengetahui kevalidan item pertanyaan kuesioner. Nilai $r$ hitung semua item pertanyaan dalam kusioner variabel dukungan organisasi $\left(\mathrm{X}_{1}\right)$, kesesuaian nilai $\left(\mathrm{X}_{2}\right)$, employee resilience $\left(\mathrm{X}_{3}\right)$, dan komitmen organisasi $(\mathrm{Y})$, adalah lebih besar dari $\mathrm{r}$ tabel $(0,750$ $0,930>0,444)$ yang berarti bahwa item-item pertanyaan atau pernyataan pada kuesioner tersebut dinyatakan valid dan dapat digunakan untuk penelitian.

\section{Uji Reliabilitas}

Reliabilitas diuji dengan cronbach alpha, dimana instrument penelitian dinilai reliable bila nilai alpha lebih besar dari $r$ table. Nilai alpha varuabel dukungan organisasi $\left(X_{1}\right)=0,947$, kesesuaian nilai $\left(\mathrm{X}_{2}\right)=0,929$, employee resilience $\left(\mathrm{X}_{3}\right)=0,929$, dan komitmen organisasi $(\mathrm{Y})=$ 0,920 . Nilai-nilai alpha croanbach pada semua variabel penelitian tersebut adalah lebih besar dari $r$ tabel sebesar 0,444. Dengan demikian maka dapat dinyatakan bahwa kuesioner atau insntrumen semua variabel penelitian ini adalah reliabel dan layak digunakan sebagai alat pengumpulan data.

\section{Uji Asumsi Klasik \\ Normalitas Data}

Uji normalitas bertujuan untuk mengetahui apakah dalam model regresi, variabel dependen dan variabel independen mempunyai data yang terdistribusi normal atau tidak.Uji normalitas menggunkan kolmogorov smirnov, hasilnya diperoleh nilai kolmogorov smirnov sebesar 1,249 dan nilai Asymp. Sig. (2-tailed) sebesar 0,088 lebih besar dari alpha 0,05. Berdasarkan nilai-nilai tersebut maka dapat dinyatakan bahwa data terdistribusi atau menyebar dengan normal. 


\section{Multikolinearitas}

Tabel 2. Hasil uji multikolinieritas

\begin{tabular}{lccc}
\hline Variabel & Tolerance & VIF & Keterangan \\
\hline Dukungan organisasi & 0,326 & 3,068 & tidak multikolinieritas \\
Kesesuaian nilai & 0,268 & 3,730 & tidak multikolinieritas \\
Employee resilience & 0,221 & 4,533 & tidak multikolinieritas \\
\hline
\end{tabular}

Sumber: Data primer yang diolah, 2020

Pada perhitungan nilai Variance Inflation Factor (VIF) menunjukkan bahwa seluruh variabel bebas memiliki nilai VIF kurang dari 10, sehingga dapat disimpulkan bahwa model regresi yang diajukan tidak terjadi masalah multikolinieritas.

\section{Heteroskedastisitas}

Pengujian ini digunakan untuk mengetahui apakah variabel pengganggu (e1) dalam persamaan regresi mempunyai varians yang sama atau tidak. Cara yang digunakan untuk mengetahui heteroskedastisitas pada penelitian ini adalah dengan metode scatter plot. Hasilnya dinyatakan bahwa tidak terjadi heteroskedastisitas dalam model regresi kedua.

\section{ANALISIS REGRESI}

Tabel 3. Rangkuman hasil uji persamaan regresi

\begin{tabular}{lccc}
\hline Koefisien & Beta & t & Sig. \\
\hline (Constant) & $-0,755$ & $-1,744$ & 0,083 \\
Dukungan organisasi & 0,301 & 7,991 & 0,000 \\
Kesesuaian nilai & 0,356 & 6,903 & 0,000 \\
Employee resilience & 0,362 & 9,518 & 0,000 \\
\hline $\mathrm{N}=190 \quad$ Probabilitas: 0,000 & & \\
$\mathrm{~F}=661,136 \quad$ & & \\
$\mathrm{R}=0,956, \mathrm{R}$ Square $=0,914$, Adjusted R Square $=0,913$ & &
\end{tabular}

Sumber: data primer diolah, 2020

Berdasarkan tabel di atas diketahui bahwa ada pengaruh dukungan organisasi $\left(\mathrm{X}_{1}\right)$, kesesuaian nilai $\left(\mathrm{X}_{2}\right)$, dan employee resilience $\left(\mathrm{X}_{3}\right)$ terhadap komitmen organisasi $(\mathrm{Y})$, yang ditunjukkan dengan nilai $R$ Square sebesar 0,914 yang berarti bahwa komitmen organisasi dipengaruhi oleh dukungan organisasi, kesesuaian nilai, dan employee resilience sebesar $91,40 \%$, dan sebesar $8,60 \%$ dipengaruhi oleh variabel lain yang tidak diteliti. Nilai $\mathrm{R}$ sebesar 0,956 mengandung arti bahwa hubungan antara dukungan organisasi, kesesuaian nilai, dan employee resilience dengan komitmen organisasi adalah sangat kuat. Nilai Adjusted $R$ Square untuk lebih mendekati ketepatan model dalam populasi, yaitu sebesar 0,913. Dari nilai tersebut dapat diartikan bahwa 91,30\% tinggi rendahnya perubahan komitmen organisasi dapat dijelaskan oleh berbagai perubahan variabel dukungan organisasi, kesesuaian nilai, dan employee resilience.

Analisis regresi menghasilkan nilai $\mathrm{F}_{\text {hitung }}$ sebesar 661,136 yang menunjukkan nilai $\mathrm{F}_{\text {hitung }}>$ $F_{\text {tabel }}(3,04)$, maka dapat dikatakan bahwa variabel dukungan organisasi, kesesuaian nilai, dan employee resilience mampu menjadi prediktor variabel komitmen organisasi. Nilai signifikansi $0,000<\alpha 0,05$ yang berarti signifikan, maka mengandung makna bahwa dukungan organisasi, 
kesesuaian nilai, dan employee resilience berpengaruh secara bersama-sama dan signifikan terhadap komitmen organisasi karyawan PD BPR BKK Purwokerto.

Berdasarkan tabel di atas dapat dihasilkan persamaan regresi sebagai berikut :

$$
Y=-0,755+0,301 X_{1}+0,356 X_{2}+0,362 Z / X_{3}+e
$$

\section{PENGUJIAN HIPOTESIS DAN PEMBAHASAN}

\section{Pengaruh dukungan organisasi terhadap organizational commitment}

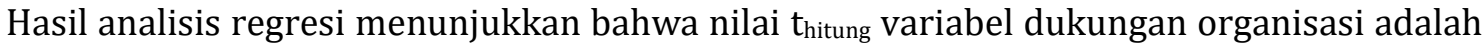
sebesar 7,991 lebih besar dari nilai tabel $(7,991>1,98)$, yang berarti dukungan organisasi berpengaruh terhadap komitmen organisasi karyawan. Nilai probabilitas atau signifikansi adalah 0,000 lebih kecil dari 0,05 $(0,000<0,05)$ yang berarti signifikan. Berdasarkan nilai tersebut, maka dapat dikatakan bahwa secara parsial terdapat pengaruh positif yang signifikan dukungan organisasi terhadap komitmen organisasi, sehingga hipotesis yang menyatakan dukungan organisasi berpengaruh positif terhadap komitmen organisasi karyawan, diterima.

Hasil ini berarti bahwa dukungan organisasi dapat dijadikan sebagai prediktor komitmen organisasi seorang karyawan, karena dapat menentukan naik turun atau tinggi rendahnya komitmen organisasi karyawan pada perusahaan tempatnya bekerja. Pengaruh yang positif dapat dimaknai bahwa semakin tinggi dukungan organisasi yang dirasakan oleh karyawan maka akan semakin tinggi pula komitmen organisasi yang dimiliki karyawan kepada PD.BPR BKK Purwokerto. Sebaliknya semakin rendah dukungan organisasi yang dirasakan oleh karyawan, maka akan semakin rendah pula komitmen organisasi yang dimiliki karyawan kepada PD BPR BKK Purwokerto.

Sebagaimana yang dikemukakan oleh Eisenberger et al., (2001) bahwa pada level persepsi dukungan organisasi yang lebih tinggi, karyawan merasa berkewajiban untuk membalas dukungan organisasi dengan cara peduli tentang kesejahteraan organisasi dan membantu mencapai tujuannya. Demikian pula dengan pendapat Eisenberger dan Rhoades (2002) menyatakan bahwa karyawan yang merasa bahwa organisasinya memberikan dukungan, menghargai hasil kerja dan peduli akan kesejahteraannya, maka karyawan akan cenderung lebih berkomitmen terhadap organisasinya. Hasil penelitian ini apabila dibandingkan dengan hasil penelitian Ardi dan Sudarma (2015) adalah sejalan karena sama-sama menunjukkan bahwa dukungan organisasi berpengaruh terhadap komitmen organisasi. Apabila dibandingkan dengan hasil penelitian Metria dan Riana (2018) juga sejalan, karena sama-sama menunjukkan bahwa dukungan organisasi berpengaruh positif dan signifikan terhadap komitmen organisasi. Hasil penelitian lainnya yang sejalan dengan hasil penelitian ini adalah hasil penelitan Abraham et al., (2016) dan Bodjrenou \& Ming (2019) yang menunjukkan dukungan organisasi berpengaruh positif sinifikan terhadap komitmen organisasi. Demikian pula dengan hasil penelitian hasil penelitian Farhad et al., (2013) dan Alijanpour et al., (2013) yang menyimpulkan bahwa persepsi dukungan organisasi berhubungan posistif signifikan dengan komitmen organisasi.

Karyawan PD BPR BKK Purwokerto merasa mendapat dukungan organisasi apabila organisasi memberi perhatian kepada mereka. Perhatian organisasi tersebut misalnya membantu karyawan saat menghadapi kesulitan, memperhatikan kesejahteraan para karyawan, memberi penghargaan kepada karyawan yang berprestasi, dan lain-lain. Perhatian yang diberikan oleh organisasi tersebut akan menimbulkan keterikatan karyawan dengan organisasi yang dengan sendirinya akan membentuk komitmen organisasi pada karyawan. Hasil penelitian ini telah membuktikan secara empirik bahwa dukungan organisasi berpengaruh terhadap komitmen organisasi karyawan PD BPR BKK Purwokerto. 


\section{Pengaruh kesesuaian nilai terhadap organizational commitment}

Hasil analisis regresi yang tertera pada Tabel 3, menunjukkan bahwa nilai $t_{\text {hitung }}$ variabel kesesuaian nilai adalah sebesar 6,903 lebih besar dari nilai $t_{\text {tabel }}(6,903>1,98)$, yang berarti kesesuaian nilai berpengaruh terhadap komitmen organisasi karyawan. Nilai probabilitas atau signifikansi adalah 0,000 lebih kecil dari 0,05 $(0,000<0,05)$ yang berarti signifikan. Berdasarkan nilai tersebut, maka dapat dikatakan bahwa secara parsial terdapat pengaruh positif yang signifikan kesesuaian nilai terhadap komitmen organisasi, sehingga hipotesis yang menyatakan kesesuaian nilai berpengaruh positif terhadap komitmen organisasi karyawan, diterima.

Hasil ini berarti bahwa kesesuaian nilai dapat dijadikan sebagai prediktor komitmen organisasi seorang karyawan, karena dapat menentukan naik turun atau tinggi rendahnya komitmen organisasi karyawan pada perusahaan tempatnya bekerja. Pengaruh yang positif dapat dimaknai bahwa semakin tinggi kesesuaian nilai yang dimiliki karyawan maka akan semakin tinggi pula komitmen organisasi karyawan kepada PD BPR BKK Purwokerto. Sebaliknya semakin rendah kesesuaian nilai yang dimiliki karyawan maka akan semakin rendah pula komitmen organisasi karyawan kepada PD BPR BKK Purwokerto.

Sebagaimana pendapat yang dikemukakan oleh Mowday \& Steers (1979) yaitu bahwa dalam ruang lingkup nilai, komitmen organisasi adalah wujud dari adanya kesesuaian antara identitas diri seorang individu dengan tujuan organisasi. Kondisi ini sesuai dengan pendapat Robbins (2013), yaitu bahwa kesesuaian nilai individu dengan kultur organisasi menjadi dasar kepuasan kerja, komitmen terhadap organisasi dan tingkat perputaran karyawan pada level yang lebih rendah. Hasil penelitian ini sejalan dengan hasil penelitian Finegan (2000) yang menjelaskan bahwa sikap individu ketika organisasi memperhatikan kesejahteraan karyawannya, maka karyawan tersebut kemungkinan besar akan berkomitmen secara aktif. Organisasi harus peduli tentang bagaimana karyawan memandang nilai-nilai dalam organisasi untuk berkomitmen terhadap organisasi yang afektif dan normatif. Hasil penelitian ini juga sejalan dengan hasil penelitian Karakurum (2005) dan Çicek \& Bicer (2014) menunjukkan bahwa kesesuaian nilai karyawan dengan nilai organisasi berpengaruh positif terhadap komitmen organisasi. Hasil penelitian ini juga sejalan dan didukung oleh hasil penelitian Thomas (2012) dan Omellas (2017) yang menunjukkan bahwa kesesuaian nilai individu dengan nilai organisasi berpengaruh signifikan terhadap komitmen organisasi.

Hal ini dapat terjadi karena karyawan yang menganggap dan merasakan nilai-nilai, budaya, iklim dan atau lingkungan kerjanya sama dengan nilai-nilai atau karakter yang dimilikinya, cenderung memiliki komitmen organisasi yang baik. Karyawan cenderung lebih dapat bertahan untuk tetap berada di tempat kerjanya, walaupun mengalami masalah dalam pekerjaannya. Namun karena merasa nyaman dalam bekerja dan tidak ada pertentangan nilai, maka karyawan tetap memiliki komitmen pada tempat kerjanya.

Dengan demikian hal ini dapat menunjukkan bahwa kesesuaian nilai yang dirasakan karyawan dengan nilai-nilai yang ada pada PD BPR BKK Purwokerto membuatnya memiliki rasa komitmen terhadap PD BPR BKK Purwokerto pada level yang sama. Secara empiris hasil penelitian ini telah membuktikan bahwa kesesuaian nilai berpengaruh positif terhadap komitmen organisasi.

\section{Pengaruh Employee Resilience Terhadap Organizational Commitment}

Hasil analisis regresi persamaan yang tertera pada Tabel 3, menunjukkan bahwa nilai

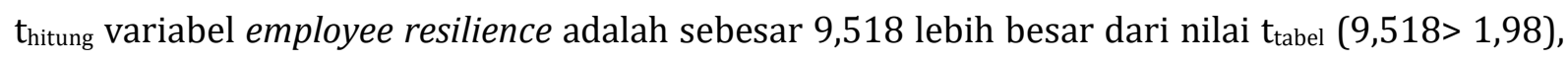
yang berarti employee resilience berpengaruh terhadap komitmen organisasi karyawan. Nilai 
probabilitas atau signifikansi adalah 0,000 lebih kecil dari 0,05 $(0,000<0,05)$ yang berarti signifikan. Berdasarkan nilai tersebut, maka dapat dikatakan bahwa secara parsial terdapat pengaruh positif yang signifikan employee resilience terhadap komitmen organisasi, sehingga hipotesis yang menyatakan employee resilience berpengaruh positif terhadap komitmen organisasi karyawan, diterima.

Hasil ini berarti bahwa employee resilience dapat dijadikan sebagai prediktor komitmen organisasi seorang karyawan, karena dapat menentukan naik turun atau tinggi rendahnya komitmen organisasi karyawan pada perusahaan tempatnya bekerja. Pengaruh yang positif dapat dimaknai bahwa semakin tinggi employee resilience, maka akan semakin tinggi pula komitmen organisasi karyawan PD BPR BKK Purwokerto. Sebaliknya semakin rendah employee resilience, maka akan semakin rendah pula komitmen organisasi karyawan PD BPR BKK Purwokerto.

Hal ini dapat terjadi karena karyawan yang memiliki employee resilience pada level yang lebih tinggi akan mengubah masalah yang dihadapi menjadi sebuah peluang dan harapan untuk berhasil dalam mencapai tujuannya, sehingga tetap bertahan dan memiliki komitmen yang baik pada PD BPR BKK Purwokerto. Sebagaimana yang dijelaskan oleh Luthans et al., (2007), bahwa resiliensi adalah peningkatan tanggung jawab dan kapasitas atau kemampuan untuk bertahan secara gigih dalam menghadapi kesulitan, konflik, kegagalan atau bahkan kejadian-kejadian positif. Dapat dikatakan bahwa resiliensi adalah kemampuan karyawan dalam menghadapi dan mengubah permasalahan yang sedang dihadapi dalam pekerjaannya dan mengubahnya menjadi sebuah peluang untuk lebih produktif. Karyawan yang tidak memiliki resilensi akan menunjukkan perilaku yang kurang memiliki komitmen organisasi, dan sebaliknya, dengan adanya resiliensi di tempat kerja diharapkan dapat mendorong komitmen organisasi. Semakin resilien seorang karyawan maka semakin tinggi kemungkinan untuk memiliki komitmen organisasi yang tinggi pula.

Hal ini sebagaimana penjelasan Luthans \& Lester (2006) dalam penelitiannya bahwa resiliensi menjadi faktor yang sangat diperlukan untuk dapat mengubah ancaman-ancaman menjadi kesempatan untuk bertumbuh, berkembang, dan meningkatkan kemampuan untuk beradaptasi demi perubahan yang baik. Oleh karena itu karyawan yang memiliki tingkat resiliensi yang tinggi cenderung akan memiliki komitmen organisasi yang baik. Hasil penelitian ini dikuatkan dengan beberapa hasil penelitian yang sejalan, yaitu penelitian yang dilakukan Paul et al., (2016) dan Hui Meng et al., (2017) dimana hasilnya menunjukkan bahwa employee resilience berpengaruh secara signifikan terhadap komitmen organisasi.

Beberapa hasil penelitian lain yang sejalan dengan penelitian ini, yaitu hasil penelitian Agyemang \& Ofel (2013) yang menunjukkan bahwa terdapat hubungan positif antara employment engagement terhadap employment commitment. Kemudian hasil penelitian Lather \& Kaur (2015) yang menyimpulkan bahwa psychological capital memiliki pengaruh positif terhadap komitmen organisasi. Data ini menunjukkan bahwa employee resilience yang dimiliki oleh karyawan mampu membuatnya memiliki komitmen yang baik pada PD BPR BKK Purwokerto. Hasil penelitian ini telah memberikan bukti secara empirik bahwa employee resilience berpengaruh positif terhadap komitmen organisasi.

\section{KESIMPULAN}

Dukungan organisasi berpengaruh positif terhadap organizational commitment karyawan PD BPR BKK Purwokerto. Pengaruh yang positif dapat dimaknai bahwa semakin tinggi dukungan organisasi yang dirasakan oleh karyawan, maka akan semakin tinggi pula komitmen organisasi yang dimiliki karyawan kepada PD BPR BKK Purwokerto. Kesesuaian nilai 
berpengaruh positif terhadap organizational commitment karyawan PD BPR BKK Purwokerto. Pengaruh yang positif dapat dimaknai bahwa semakin tinggi kesesuaian nilai yang dimiliki karyawan, maka akan semakin tinggi pula komitmen organisasi karyawan kepada PD BPR BKK Purwokerto. Employee resilience berpengaruh positif terhadap organizational commitment karyawan PD BPR BKK Purwokerto. Pengaruh yang positif dapat dimaknai bahwa semakin tinggi emlpoyee resilience yang dimiliki karyawan, maka akan semakin tinggi pula komitmen organisasi karyawan kepada PD BPR BKK Purwokerto.

\section{KETERBATASAN PENELITIAN}

Penelitian ini dimaksudkan untuk memotret secara khusus kondisi karyawan di PD BPR BKK Purwokerto. Oleh karena itu, hasil penelitian ini tidak dapat digeneralisir untuk semua karyawan di industri perbankan sejenis ataupun perbankan umum lainnya. Kurang spesifiknya karakteristik karyawan yang diteliti sehingga membuat penelitian ini kurang terfokus pada satu karakteristik karyawan. Peneliti juga tidak menentukan kriteria yang lebih spesifik misalnya dengan melihat status kepegawaian, masa kerja dan jabatan karyawan. Adanya keterbatasan penelitian dengan menggunakan kuesioner yaitu terkadang jawaban yang diberikan oleh responden tidak menunjukkan keadaan yang sesungguhnya. Adanya kemungkinan social desirability dalam pengisian skala yang dapat mempengaruhi hasil penelitian. Hal ini dikarenakan karyawan akan menjawab jawaban yang sekiranya diterima dalam lingkungan sekitar dan bukan karena keadaan dirinya yang sebenarnya.

\section{SARAN}

Dukungan organisasi berdasarkan penelitian ini berpengaruh terhadap organizational commitment. Oleh karena itu PD BPR BKK Purwokerto hendaknya meningkatkan dukungan organisasi kepada para karyawannya di masa yang akan datang dengan cara memberikan bonus kepada karyawan yang berprestasi, memperdulikan keadaan karyawan, karyawan diperlakukan dengan adil dan bermartabat, sehingga karyawan memiliki ketangguhan dalam bekerja dan pada akhirnya berkomitmen pada perusahaan. Kesesuaian nilai berdasarkan penelitian ini berpengaruh terhadap organizational commitment. Oleh karena itu PD BPR BKK Purwokerto hendaknya lebih memperhatikan kesesuaian nilai yang dimiliki para karyawan, dengan menciptakan budaya kerja yang sesuai dengan nilai-nilai individu, menciptakan suasana kerja yang nyaman, sehingga karyawan tetap bertahan untuk bekerja di perusahaan karena merasa nyaman dengan nilai-nilai perusahaan yang sesuai dengan pribadinya dan pada akhirnya akan menimbulkan komitmen organisasi. Employee resilience berdasarkan penelitian ini berpengaruh terhadap organizational commitment. Oleh karena itu PD BPR BKK Purwokerto hendaknya meningkatkan employee resilience para karyawannya dengan cara saling memberikan support antar pegawai dan atasan juga memberi support yang lebih kepada para bawahannya, mengadakan pelatihan kerja yang terintegrasi, outbond workshop serta reward and punishment program untuk meningkatkan kemampuan serta intelegensi karyawan untuk membangun sebuah tim kerja yang lebih produktif.

\section{DAFTAR PUSTAKA}

Abraham, Jocelyne; Stéphane Renaud dan Jean-Yves Saulquin. 2016. Relationships Between Organizational Support, Organizational Commitment and Retention : Evidence From High Potential Employees. Global Journal of Business Research.Vol. 10, No. 1, pp. 11-26. 
Agyemang, Collins Badu dan Samuel Batchison Ofei. 2013. Employee Work Engagement and Organizational Commitment : A Comparative Study of Private and Public Sector Organizations in Ghana. European Journal of Business and Innovation Research. Vol.1, No.4. pp.20-33.

Allen, N., \& Meyer, J. 1990. The Measurement and Antecedents of Affective, Continuance and Normative Commitment. Journal of Occupational Psychology, 63, 1-18.

Alijanpour, Marziyeh; Morteza Dousti dan Abbas Khodayari. 2013. The relationship between the perceived organizational support and organizational commitment in staff (A case study: General office for sport and the youth, Mazandaran province). European Journal of Experimental Biology. Vol. 3, No.5. pp.:165-171.

Ardi, Raka Tri Bayu dan Ketut Sudarma. 2015. Pengaruh Persepsi Dukungan dan Keadilan Organisasi Terhadap Organizational Citizenship Behavior dengan Komitmen Organisasional Sebagai Variabel Intervening. Management Analysis Journal. vol. 4 . no. 2. pp. 142-152.

Atmoko, Satrio Dwi dan Anita Listiara. 2012. The Relationship Between Resilience with continuence Commitment of Honorer Teacher in UPTD Pendidikan Kecamatan Banyumanik Semarang. Jurnal Psikologi. Vol, 1, No,1, Hal. 31-46.

Bodjrenou Kossivi dan Xu Ming. 2019. Assessment of the Effect of Organizational Support and Investment in Employee Development on Affective Commitment. International Business Research; Vol. 12, No. 3. Pp. 153-164.

Çicek, Isık dan Ismail Hakkı BIÇER. 2014. Values Congruence and Relational Demography as an Antecedent of Organizational Commitment. International Journal of Business and Management Studies. Vol 6, No 1, pp. 16-31.

Chen, Z. X., \& Francesco, A. M. 2003. The relationship between the three components of commitment and employee performance in China. Journal of Vocational Behavior, 62(3), 490-510.

Edwards, B. D. \& Cable, S. T 2009, Relationships between facets of job satisfaction and task and contextual performance, Applied Psychology : An InternationalReview, 57(3), 441-465.

Eisenberger, R., Fasolo, P., and Davis-LaMastro, V., 1990, Perceived organizational support and employee diligence, commitment, and innovation, Journal of Applied Psychology, Vol.75, pp 51-59.

Eisenberger, R., Armeli, S., Rexwinkel, B., Lynch, P. D., \& Rhoades, L. 2001. Reciprocation of perceived organizational support. Journal of Applied Psychology, 86(1), 42-51.

Eisenberger, R, and Rhoades, L. 2002. Perceived organizational support : A review of the literature. Journal of Applied Psychology, 87, 698-714.

Esra Alniaci, Umit Alniacik, Serhat Erat dan Kulugin Akcin 2013, Does person-organization fit moderate the effects of affective commitment and job satisfaction on turnover intentions. Procedia - Social and Behavioral Sciences 99 ( 2013 ) $274-281$.

Farhad, Abdollah; Piri, Moosa Associate dan Azimi, Mohammad. 2013. The relationship between Perceived Organizational Support and Organizational Commitment among faculty members. Australian Journal of Basic and Applied S ciences. Vol.7, No.4. pp.: 475-479.

Finegan, J. E. 2000. The impact of person and organizational values onorganizational commitment. Journal of Occupational and Organizational Psychology, 73, 149-169.

Grotberg, E. H. 1996. The International Resilience Research Project. Birmingham : International Resilience Project.

Hui Meng, Yang Luo, Lu Huang, Jianbing Wen, Jizhu Ma \& Juzhe Xi, 2017, On the relationships of resilience with organizational commitment and burnout : a social exchange perspective. The International Journal of Human Resource Management. pp. 1-20.

Karakurum, Müge. 2005. The Effects of Person-Organization Fit on Employee Job Satisfaction, Performance and Organizational Commitment in a Turkish Public Organization. Tesis. Universitas Teknik-Turki.

Kristof, A. 1996. Person-Organization Fit : An Integrative Review of Its Conceptualizations, Measurement, and Implications. Journal of Personnel Psychology. 49: 1-49. 
Lather, Anu Singh dan Simran Kaur. 2015. Psychological Capital as Predictor of Organizational Commitment and Organizational Citizenship Behavior. The International Journal of Indian Psychology. Volume 2, Issue 4, pp. 102-112.

Luthans, F., Vogelgesang, G., R., \& Lester, P., B.2006. Developing the psychological capital of resiliency. Human Resource Development Review, 5 (1), 25-44.

Luthans, F., Youssef, C., M., Avolio, B.,\& Avev, J.B. 2007. Psychological capital: Developing the human competitive edge. New York : Oxford University Press.

Masten, A, S., \& Reed, M. G. 2002. Resilience in development. In S. R. Snyder \& S. J. Lopez (Eds.), The handbook of positive psychology. Oxford, England: Oxford University Press.

Mathis, R.L., dan Jackson, J.H. 2006. Manajemen Sumber Daya Manusia, Buku I. Jakarta : Salemba Empat.

Metria. Ketut dan I Gede Riana. 2018. Pengaruh Dukungan Organisasi Terhadap Komitmen Organisasional dan Kinerja Karyawan. E-Jurnal Ekonomi dan Bisnis Universitas Udayana. Vol, 7. No. 9 . pp. 21172146.

Mowday, R. T., \& Steers, R. M. 1979. Measurement of organizational commitment. Journal of vocational behavior, 224-247.

Omellas, Rebecca Emily. 2017. Do Counter-Ideal Values Matter? Organizational Outcaomes of Value Congruence. Tesis. San Francisco State University.

Paul, Happy, Umesh Kumar Bamel, and Pooja Garg. 2016. Employee Resilience and OCB : Mediating Effects of Organizational Commitment. The Journal for Decision Makers , 41(4) 308-324.

Robbins, S. P., \& Judge, T. A. 2013. Organizational Behavior (Fifteenth ed.). Eidenburgh Gate, Harlow, Essex : Pearson Education Limited.

Thomas, Tammara Petrill. 2013. The Effect of Personal Values, Organizational Values, and PersonOrganization Fit on Ethical Behaviors and Organizational Commitment Outcomes among Substance Abuse Counselors: A Preliminary Investigation. Disertation, University of Iowa. 